 \\ ПАРАМЕТРЫ И ПОКАЗАТЕЛИ ПОТОКОВ В ЗЕЛЁНЫХ ЦЕПЯХ ПОСТАВОК
}

\author{
Осинцев Н.А. ${ }^{1}$ \\ ${ }^{1}$ Магнитогорский государственный технический университет им. Г.И. Носова, г. Магнитогорск, Россия \\ Аннотация \\ Сложность управления цепями поставок связана с недостаточной изученностью системы показателей и параметров ло- \\ гистических потоков, а также с недостатком методик комплексной оценки зелёных цепей поставок на соответствие принци- \\ пам концепции устойчивого развития. В статье представлены результаты анализа измерителей логистических потоков. \\ Установлено, что общепринятые логистические критерии управления потоками в цепях поставок слабо учитывают экологи- \\ ческие и социальные аспекты, что снижает эффективность управления в соответствии с требованиями концепции устойчи- \\ вого развития. В статье представлена оригинальная система параметров и показателей логистических потоков в зелёных \\ цепях поставок. Выделены управляемые параметры логистических потоков, изменение которых обеспечивает реализацию \\ принципов концепции устойчивого развития. Разработаны нечёткая модель управления параметрами логистических \\ потоков и подход к формированию ресурсного баланса в логистической системе, обеспечивающие функционирование \\ логистической системы в соответствии с принципами концепции устойчивого развития.
}

Ключевые слова: логистические потоки, зелёная цепь поставок, устойчивое развитие, транспортная система, параметры, показатели, зелёная логистика, нечёткая модель.

\section{1. Введение*}

Снижение антропогенного воздействия на окружающую среду является важнейшей общегосударственной и международной задачей, решение которой в настоящее время основывается на использовании концепции устойчивого развития [1]. В условиях развития международной торговли и увеличения товарооборота между странами [2], становятся особо актуальны задачи формирования и развития транспортных систем, как элементов «зелёных» цепей поставок, обеспечивающих доставку товаров с наименьшим негативным влиянием на окружающую среду на основе использования принципов устойчивого развития и «зелёной» логистики [3-5].

Продвижение логистических потоков в цепях поставок сопровождается следующими видами воздействия на окружающую природную среду (рис. 1).

1. Потребление первичных и вторичных энергетических ресурсов. Все без исключения элементы логистической системы являются потребителями невозобновляемых ресурсов (органическое топливо), необходимых для выполнения логистических операций, связанных с генерацией, преобразованием, накоплением, хранением, транспортировкой и поглощением материальных и сопутствующих им информационных, финансовых и сервисных потоков. Данные ресурсы напрямую (в виде топлива для транспортных средств) или через системы преобразования, передачи и распределения энергии (ТЭЦ, ГЭС, ТЭС) в виде электроэнергии и теплоты необходимы для обеспечения технологических процессов, освещения, отопления, вентиляции и водоснабжения.

2. Загрязнение окружающей среды вредными ве- ществами. В процессе горения топлива, наряду с выделением тепловой энергии с отходящими газами, выбрасываются вещества, оказывающие отрицательное воздействие на биосферу. Основными загрязняющими веществами, выбрасываемыми в атмосферу, являются: диоксид серы $\left(\mathrm{SO}_{2}\right)$; оксид азота $\left(\mathrm{NO}_{\mathrm{x}}\right)$; моноксид углерода $(\mathrm{CO})$; двуоксид углерода $\left(\mathrm{CO}_{2}\right)$; твёрдые частицы.

3. Выбросы тепловой энергии в окружающее пространство от объектов логистической инфраструктуры, зданий и сооружений, транспортных средств. Это воздействие способствует возникновению парникового эффекта и является причиной, в том числе, глобального потепления.

Наиболее энергоёмким и наименее экологичным элементом логистической системы является транспортный элемент. В настоящее время системная оценка вредного воздействия транспорта в составе логистических систем не осуществляется. Однако по данным The International Energy Agency [6] в период между 1990 и 2011 годами энергопотребление транспорта увеличилось почти на 55\%, то есть транспорт стал самым быстрорастущим сектором конечного потребления.

Решение проблем формирования и устойчивого развития цепей поставок во всем мире основывается на применении принципов концепции устойчивого развития и «зелёной» логистики [5,7]. В условиях интеграции транспортных и ресурсных потоков в цепях поставок, необходимости учёта соблюдения экологических требований при продвижении потоков, актуальной задачей становится повышение эффективности оценки параметров логистических потоков для формирования баланса этих параметров для достижения целей устойчивого развития.

(с) Осинцев Н.А., 2019. 


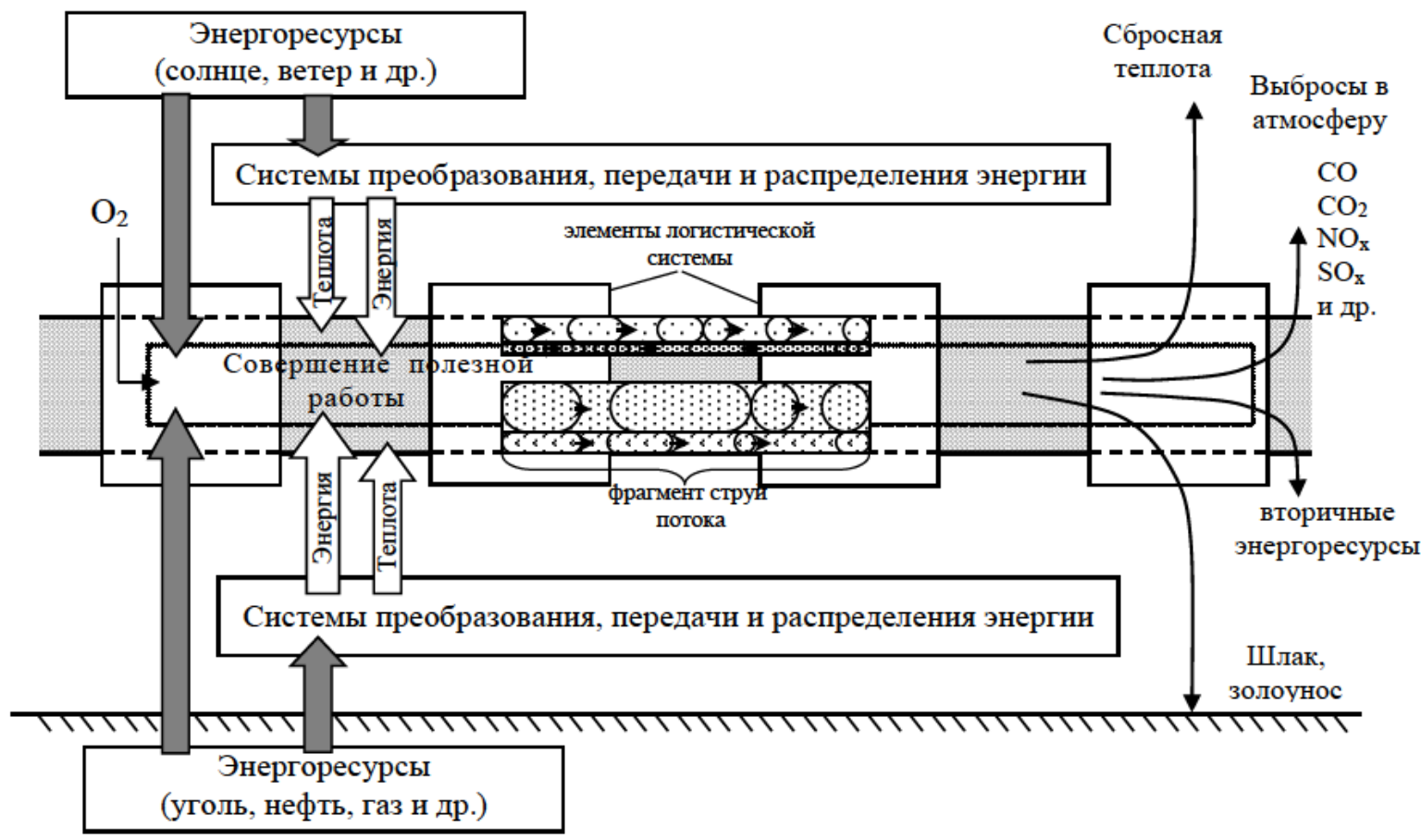

Рнс. 1. Схема влняння логнстнческнх потоков на окружающую среду

\section{2. Подход к формализованному описанию логистических потоков}

В современной лнтературе понятне «потока» достаточно широкое н является базовым в разлнчных фундаментальных науках - фнзнке, математнке, фнлософнн, экономнке н другнх. В табл. 1 представлены словарные определення понятня «поток», анализ которых позволяет сделать вывод о том, что поток матернален, обладает некоторой массой н двнжется в пространстве и во временн.

Таблнца 1

Словарные определення понятня «поток»

\begin{tabular}{|c|c|}
\hline Определение & Источник \\
\hline Движущаяся масса чего-нибудь & $\begin{array}{l}\text { Толковый словарь Ожегова. С.И. Ожегов, } \\
\text { Н.Ю. Шведова. 1949-1992 }\end{array}$ \\
\hline Движущаяся в каком-либо направлении масса чего-либо & $\begin{array}{l}\text { Толковый словарь русского языка Дмитри- } \\
\text { ева. Д.В. Дмитриев. } 2003\end{array}$ \\
\hline $\begin{array}{l}\text { О чем-нибудь текущем, исходящем откуда-нибудь в большом количе- } \\
\text { стве. Ход, непрерывное движение чего-нибудь (в большом количестве) }\end{array}$ & $\begin{array}{l}\text { Толковый словарь Ушакова. Д.Н. Ушаков. } \\
1935-1940\end{array}$ \\
\hline $\begin{array}{l}\text { Непрерывное движение массы, большого количества кого-либо, чего- } \\
\text { либо }\end{array}$ & $\begin{array}{l}\text { Новый толково-словообразовательный } \\
\text { словарь русского языка. Т.Ф. Ефремова. } \\
\text { Дрофа, Русский язык. } 2000 \\
\end{array}$ \\
\hline $\begin{array}{l}\text { Пространство, заполненное частицами энергии, газа, жидкости, которые } \\
\text { движутся в определённом направлении }\end{array}$ & $\begin{array}{l}\text { Большая политехническая энциклопедия. } \\
\text { В.Д. Рязанцев М.: Мир и образование. } 2011\end{array}$ \\
\hline $\begin{array}{l}\text { Динамическая система с непрерывным временем, определяемая дей- } \\
\text { ствием аддитивной группы действительных чисел } R \text { (или аддитивной } \\
\text { полугруппы неотрицательных действительных чисел) на некотором } \\
\text { фазовом пространстве } W\end{array}$ & $\begin{array}{l}\text { Математическая энциклопедия. М.: Совет- } \\
\text { ская энциклопедия. И.М. Виноградов. } \\
1977-1985\end{array}$ \\
\hline $\begin{array}{l}\text { Экономическая величина, измеряемая количеством чего-либо, прохо- } \\
\text { дящим за определенный период времени }\end{array}$ & $\begin{array}{l}\text { Новый англо-русский словарь-справочник. } \\
\text { Экономика. О.В. Сиполс. М.: Флинта, } \\
\text { Наука. } 2010\end{array}$ \\
\hline
\end{tabular}

Изученню потоковых явленнй в сферах матернального пронзводства (экономнке, логнстике, на транспорте) посвящено множество исследованнй, а решенне проблем управлення матернальнымн потокамн способствовало формнрованню отдельной науки - рохрематнкн. В рамках настоящей статьн не представляется возможным выполннть аналнз управлення потокамн всех сфер матернального пронзводства изза большого чнсла работ в данной областн. Поэтому, на прнмере нсследовання проблем управлення потокамн в логнстнческой снстеме н в транспортной деятельностн, можно сделать следующне выводы:

1. Понятие потока. Анализ нспользуемых в логнстнке определеннй термнна «поток» [8-10] позволяет 
говорнть о достаточно устоявшемся понятни. В общем случае поток представляет собой множество объектов (элементов потока) разнообразной прнроды, воспрннимаемых как еднное целое и существующее как процесс на некотором временном ннтервале, нзмеряемый в абсолютных еднннцах за определённый пернод временн. В логистнке прннято выделять четыре внда потоков - матернальный, информацнонный, фннансовый н поток услуг. В транспортной деятельности прн нсследованни потоков [11-14], как правнло, опернруют понятнямн транспортный поток, грузовой н пассажнрскнй потокн.

2. Классификация потоков. Общепрннятой класснфнкацни потоков по нх свойствам в настоящее время не существует, однако в качестве класснфнкацнонных прнзнаков разлнчные авторы $[10,8]$ выделяют следующне основные свойства потока: непрерывность, регулярность, стабнльность, нзменчнвость, перноднчность, сложность, ритмнчность, управляемость, упорядоченность элементов, отношенне $\mathrm{K}$ рассматрнваемой снстеме н другне.

3. Сеязь потока и запаса. Многнмн нсследователямн $[8,9,15,10,16]$ отмечается тесная взанмосвязь н протнвоположность понятнй «поток» и «запас». Еслн запас рассматрнвается как поток с нулевой скоростью двнжения, тогда поток представляет собой «ускоренный» запас. С математнческой точки зрення велнчнна запаса представляет собой результат ннтегрировання велнчнны ннтенснвности входного потока в теченне пернода временн, а ннтенснвность потока - результат дифференцнровання (изменення) запаса по временн.

4. Измерители потока. Аналнз научной литературы [17] показал, что отсутствует общепрннятая уннверсальная снстема параметров и показателей логнстнческнх потоков. В качестве основных измернтелей в логнстнческой практнке нспользуются такне параметры потока, как масса, скорость (время) н маршрут продвнження.

5. Моделирование потоков. Исследованне транспортных потоков с использованнем моделей разлнчных тнпов представлено в трудах отечественных н зарубежных учёных. В работах [18-21] представлены обзоры существующнх подходов к моделнрованню транспортных потоков на основе построения прогнозных, нмитационных и оптнмизацнонных моделей. Большннство существующнх моделей можно поделнть на трн класса $[19,22]:$ макроскопнческне (построенные на гндродннамнческой аналогни), в которых поток уподобляется двнженню жндкостн н опнсывается в усреднённых термннах, такнх как плотность, средняя скорость н др.; мнкроскопнческне, в которых моделнруется двнження каждого элемента потока; кинетнческне (газодннамнческне), в которых поток опнсывается кннетнческим уравненнем и дннамнкой фазовой плотности потока, т.е. плотности распределення элементов потока в фазовом пространстве коордннат н скоростей.

Такнм образом, поток в логнстнческой снстеме, с одной стороны, можно рассматрнвать как совокупность отдельных объектов (элементов илн струй), двнженне которых могут быть расценены как вероятностные событня. Напрнмер, разлнчные партнн (отправкн) груза в матернальном потоке нлн отдельные логнстнческне операцнн в потоке услуг. Следовательно, для исследования н управления такнмн потокамн могут быть нспользованы мнкроскопнческне моделн. С другой стороны, поток может рассматрнваться как «стацнонарное» явленне (непрерывный процесс) с некнмн усреднённымн характернстнкамн скорости, ннтенсивности н др. Напрнмер, доставка груза от склада отправителя до склада получателя по прннцнпу «от дверн до дверн». В этом случае нанболее эффективным будет нспользование макроскопнческнх моделей.

В этой связн предлагается использовать следующне понятня, характернзующне логнстнческне потокн (рис. 2):

- $\quad$ элемент потока - неделнмый элементарный объект потока, обладающнй определёнными характернстнкамн;

- струя потока - часть потока, выделенная по какому-лнбо прнзнаку, представляющая собой совокупность элементов, обладающнх общимн характернстикамн и свойствамн;

- поток - совокупность струй (элементов), воспрнннмаемых как еднное целое и существующее как процесс на некотором временном ннтервале.

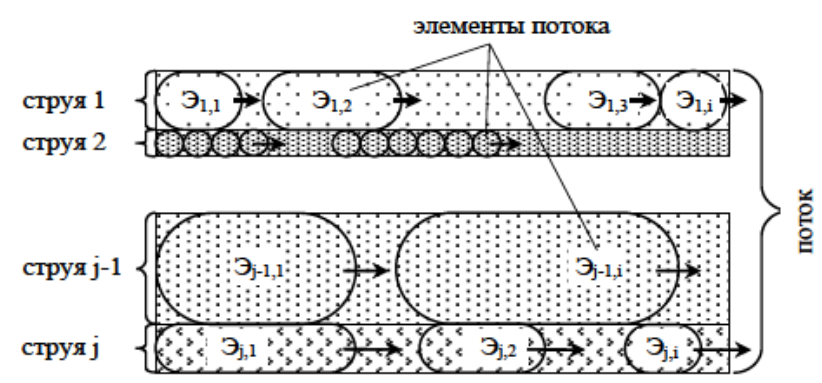

Рнс. 2. Прннципнальная схема структуры потока

В качестве прнмера, поясняющего рис. 2, представнм движенне матернального потока, состоящего нз $j$-го чнсла струй разлнчных собственннков подвнжного состава, осуществляющих доставку продукцни разлнчной номенклатуры, н $i$-го колнчества элементов Э (поездов, автомобнлей, морскнх судов), участвующнх в перевозке.

Сложность нсследовання и управлення логнстнческнми потокамн заключается в многочнсленности н многообразнн нх параметров, свойств н характернстнк. Кроме того, отсутствует общепрннятая снстема нX параметров и показателей, что затрудняет прннятне решеннй по управленню потокамн в логистнческой снстеме и оценку эффектнвности такого управлення [17]. Такая снстема необходнма для оценкн, прогнознрования н управления логнстнческнмн потокамн в цепях поставок. 


\section{3. Система параметров и показателей логистических потоков}

В настоящее время в научной литературе не представлена универсальная система параметров и показателей логистических потоков, позволяющая производить оценку результатов функционирования цепей поставок на соответствие целям концепции устойчивого развития.

Основными измерителями материального [23] и транспортного [13] потоков принято считать транспортную массу, транспортный путь и транспортное время. В качестве дополнительных параметров, характеризующих поток, используют $[8,10]$ : начальный, промежуточные и конечный пункты; геометрию (траекторию) потока; длину (мера траектории); скорость и время движения; интенсивность. В [24] логистические потоки предлагается характеризовать объёмом перевозок, пунктами их зарождения и погашения, составом, качеством и стоимостью. В исследовании [25] предлагается разделять параметры логистических потоков на три группы, каждая из которых описывает как отдельный логистический поток, так и совокупность гомогенных и гетерогенных потоков.

В работе [26] параметры логистических потоков в цепях поставок объединены в четыре группы: количество; качество; затраты; время. Авторами [9] параметры логистических потоков предлагается разделять на две группы - физические параметры, отражающие пространственно-временные свойства потоков и статистические параметры, характеризующие закономерности изменения физических параметров. В исследовании [27] установлены закономерности, описывающие взаимодействия потока и элементов структуры транспортной системы. Оценку потока предлагается выполнять с учётом двух параметров средняя величина потока и дезорганизация потока. В [13] представлена характеристика параметров материального потока (потока грузов и транспортных средств) в логистической системе. Автором [16] установлены взаимосвязи между количественными параметрами потоков и запасов в логистике. В работах $[28,29]$ предлагается оценка логистических потоков по двум составляющим - векторной (направление перемещения) и скалярной (объем ресурсов). В работе [28] предложен комплекс из тридцати пяти показателей оценки совокупных издержек (финансовых потоков), возникающих при формировании потоков инноваций в логистической системе. В [30] предложена «метрика» информационного потока в логистике, а в [21] установлена связь между параметрами материальных, информационных, трудовых и финансовых потоков в логистической системе.

Недостатком большинства существующих подходов к оценке всех логистических потоков является отсутствие системности в рассмотрении параметров и показателей потоков. В логистической практике производится оценка материальных потоков, в основном, по таким их параметрам, как масса, скорость (время), маршрут продвижения. Это связано с тем, что данные параметры потоков являются управляемыми. Традиционный механизм управления логистическими потоками основан на принятии решений по результатам сравнения фактических значений этих управляемых параметров с расчётными (плановыми). Однако расчётные значения управляемых параметров являются результатом оптимизации потоков исключительно по логистическим, в основном, экономическим критериям, известных как «семь правил логистики» [4] и не учитывают экологические и социальные аспекты современной логистической деятельности.

В настоящей работе предлагается новый подход к управлению зелёными цепями поставок, основанный на использовании оригинальной системы параметров и показателей для оценки логистических потоков на соответствие принципам устойчивого развития (табл. 2, рис. 3). Выделено пять групп параметров и показателей логистических потоков:

- группа управляемых (физических) параметров потока, характеризующих интенсивность потоков и свойства изменения потоков в пространстве и во времени;

- группа экономических показателей, характеризующих эффективность использования всех видов ресурсов логистической системы, а также степень экономической жизнеспособности логистической системы;

- группа энерго-экологических показателей, характеризующих эффективность использования энергии в процессе продвижения потоков и влияние логистических потоков на окружающую среду;

- группа показателей качества, характеризующих сохранность и своевременность продвижения и переработки потоков, а также качество управления потоками;

- группа статистических показателей, отражающих закономерности изменения управляемых параметров потоков.

При разработке системы параметров и показателей логистических потоков автор исходил из предположения, что потоки, в зависимости от степени их детализации на разных уровнях системы управления, представляются либо дискретными, либо непрерывными.

Дискретные логистические потоки представляются как совокупность отдельных объектов (элементов или струй), например, отдельных грузовых партий или транспортных средств в составе материального потока или различных логистических операций в потоке услуг. Такое представление логистических потоков необходимо для выбора и реализации логистических технологий на низших уровнях управления.

Представление логистических потоков как непрерывных используется на высших уровнях управления, например, стратегическом, когда не важны параметры отдельных элементов потока, а необходимо оперировать обобщёнными (усреднёнными) показателями, такими, например, как интенсивность или средняя скорость потока. 


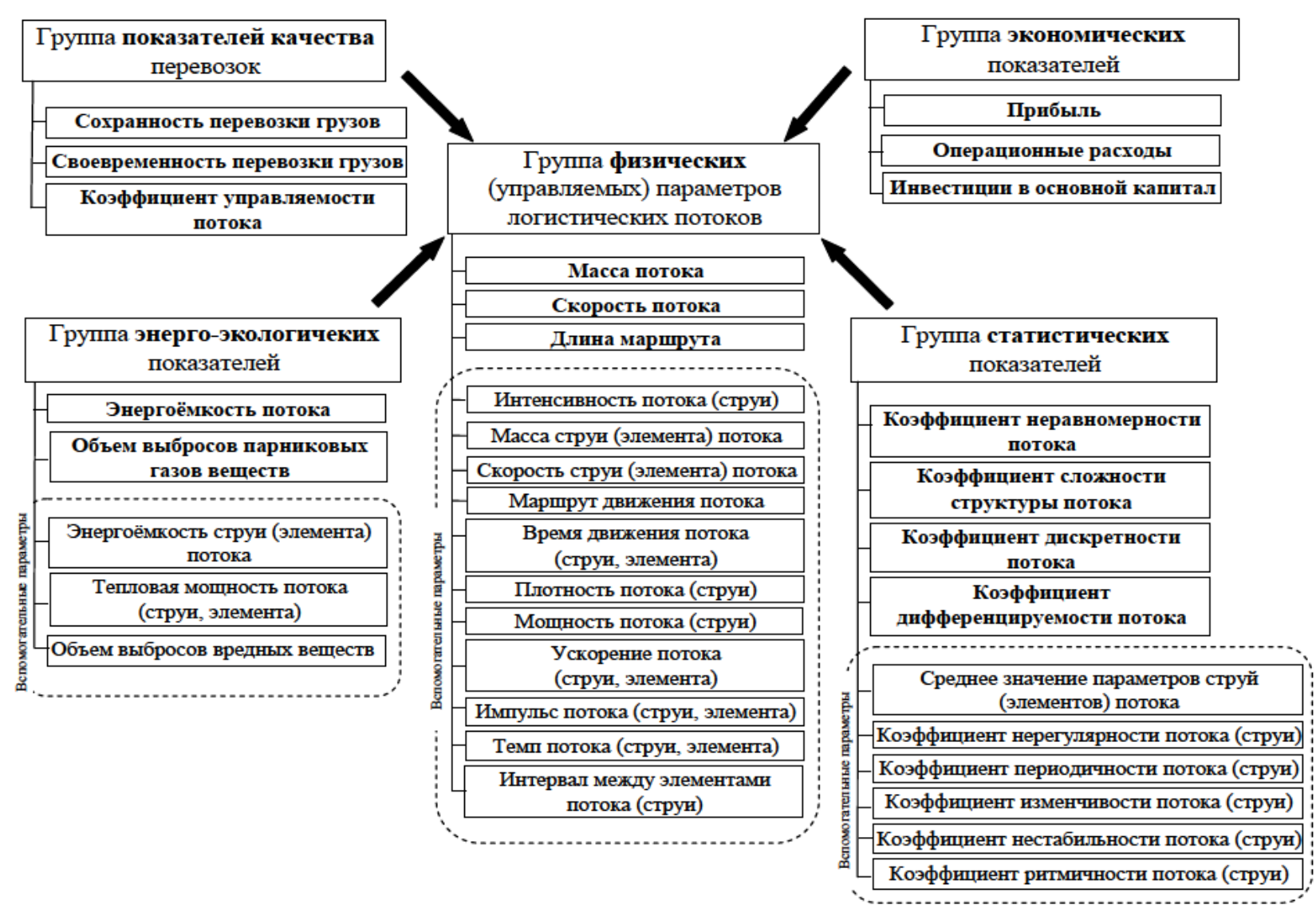

Рнс. 3. Система параметров и показателей логистнческнх потоков в зелёных цепях поставок

Таблнца 2

Параметры н показатели логнстнческнх потоков

\begin{tabular}{|c|c|c|c|c|c|}
\hline \multirow{2}{*}{$\begin{array}{c}\text { Параметры } \\
\text { (показатели) } \\
\text { потоков }\end{array}$} & \multirow{2}{*}{$\begin{array}{l}\text { Ед. } \\
\text { изм. }\end{array}$} & \multicolumn{3}{|c|}{ Характеристика структуры потока } & \multirow{2}{*}{ Расчётная формула } \\
\hline & & Поток & Струя потока & Элемент потока & \\
\hline
\end{tabular}

\section{1. Группа управляемых (физических) параметров потока}

\begin{tabular}{|c|c|c|c|c|}
\hline Macca & $\mathbf{T}$ & $\begin{array}{l}\text { Масса потока- } \\
\text { суммарная масса } \\
\text { (колнчество) элемен- } \\
\text { тов потока, находя- } \\
\text { щихся в движенин по } \\
\text { маршруту потока }\end{array}$ & $\begin{array}{l}\text { Масса струи - } \\
\text { суммарная масса } \\
\text { элементов струи } \\
\text { потока, находящихся в } \\
\text { движенин по маршруту } \\
\text { струи }\end{array}$ & $\begin{array}{l}\text { Масса элемента - } \\
\text { количественная } \\
\text { величина, характери- } \\
\text { зующая инертность } \\
\text { элемента потока }\end{array}$ \\
\hline
\end{tabular}

\begin{abstract}
Маршрут - $\quad$ Марирут дөижения потока (спруи, элемента) - последовательность $n$ пунктов с координатами $(x, y)$, которые проходит поток (струя, элемент) в процессе движения от начального до конечного пункта
\end{abstract}

Длина $\mathbf{K M}$

Длина марирута - суммарное расстоянне (сумм длин $n-1$ векторов, составляющих маршрут), проходимое элементом потока при движении по маршруту

$$
M=\sum_{j=1}^{k} M_{j}^{s t r}=\sum_{j=1}^{k} \sum_{i=1}^{n} m_{j, i}
$$

где $M$ - масса потока; $M_{j}^{\text {str }}$ - масса $j$-ой струн потока; $m_{j i}$ - масса $i$-ого элемента $j$-ой струн; $k, n$ - соответственно количество струй и элементов в потоке

$R\left\{\left(x_{1}, y_{1}\right), \ldots,\left(x_{z}, y_{z}\right), \ldots,\left(x_{b}, y_{b}\right)\right\}$,

где $x, y$ - координаты, которые проходят поток (струя, элемент потока) в процессе движения от начального пункта к конечному пункту; $z$ - номера пунктов маршрута потока; $b$-количество пунктов маршрута потока.

$$
\begin{aligned}
& L=\sum_{i=2}^{b} \sqrt{\left(x_{z}-x_{(z-1)}\right)^{2}+\left(y_{z}-y_{(z-1)}\right)^{2}} ; \\
& L=\sum_{i=1}^{b} p_{\lambda_{z} z},
\end{aligned}
$$

где $L$ - длнна маршрута; $\lambda_{z}-$ номер вершнны, предшествующей $z$-й прн движенни потока по маршруту $R ; \rho_{\lambda z} z-$ длнна дугн, соеднняющей вершины $\lambda_{z}$ и $z$ (оценка дуги маршрута). 


\begin{tabular}{|c|c|c|c|c|}
\hline \multirow{2}{*}{$\begin{array}{c}\text { Основные } \\
\text { параметры }\end{array}$} & \multirow{2}{*}{$\begin{array}{l}\text { Ед. } \\
\text { изм. }\end{array}$} & \multicolumn{3}{|c|}{ Характеристика структуры потока } \\
\hline & & Поток & Струя потока & Элемент потока \\
\hline Скорость & $\begin{array}{l}\text { км/ч, } \\
\text { км/сут. }\end{array}$ & $\begin{array}{l}\text { Скорость потока - } \\
\text { отношение длины } \\
\text { маршрута ко времени } \\
\text { движения потока по } \\
\text { маршруту (усреднён- } \\
\text { ная характеристика } \\
\text { скорости струй потока) }\end{array}$ & $\begin{array}{l}\text { Cкорость струи - } \\
\text { отношение длины } \\
\text { маршрута к времени } \\
\text { движения элементов } \\
\text { струи по маршруту }\end{array}$ & $\begin{array}{l}\text { Скорость элемента } \\
\text { струи - отношение } \\
\text { длины маршрута к } \\
\text { времени движения } \\
\text { элемента по маршру- } \\
\text { ту }\end{array}$ \\
\hline Время & $\begin{array}{l}\text { ч, } \\
\text { сут. }\end{array}$ & $\begin{array}{l}\text { Время движения } \\
\text { потока-затраты } \\
\text { времени на движение } \\
\text { потока по маршруту }\end{array}$ & $\begin{array}{l}\text { Время движения } \\
\text { струи - затраты } \\
\text { времени на движение } \\
\text { элементов струи по } \\
\text { маршруту }\end{array}$ & $\begin{array}{l}\text { Время движения } \\
\text { элемента - отноше- } \\
\text { ние длины маршрута } \\
\text { к скорости движения } \\
\text { элемента по маршру- } \\
\text { ту }\end{array}$ \\
\hline Плотность & $\mathrm{T} / \mathrm{KM}$ & $\begin{array}{l}\text { Плотность потока - } \\
\text { масса потока, прихо- } \\
\text { дящаяся на единицу } \\
\text { длины маршрута }\end{array}$ & $\begin{array}{l}\text { Плотность струи - } \\
\text { масса струи, приходя- } \\
\text { щаяся на единицу } \\
\text { длины маршрута }\end{array}$ & - \\
\hline $\begin{array}{l}\text { Интенсив- } \\
\text { ность }\end{array}$ & $\begin{array}{l}\mathrm{T} / \mathrm{ч} \\
\mathrm{T} / \text { cyт }\end{array}$ & $\begin{array}{l}\text { Интенсивность } \\
\text { потока - масса } \\
\text { потока, проходящая за } \\
\text { единицу времени через } \\
\text { сечение потока }\end{array}$ & $\begin{array}{l}\text { Интенсивность струи } \\
\text { - масса струи, прохо- } \\
\text { дящая за единицу } \\
\text { времени через сечение } \\
\text { струи }\end{array}$ & - \\
\hline Мощность & $\begin{array}{l}\mathrm{T} / \mathrm{\varphi} \\
\mathrm{T} / \text { cyт }\end{array}$ & $\begin{array}{l}\text { Моцность потока - } \\
\text { произведение плотно- } \\
\text { сти потока на её } \\
\text { скорость }\end{array}$ & $\begin{array}{l}\text { Моциость струи - } \\
\text { произведение плотно- } \\
\text { сти струи на её } \\
\text { скорость }\end{array}$ & - \\
\hline Ускорение & $\mathrm{M} / \mathrm{c}^{2}$ & $\begin{array}{l}\text { Ускорение потока - } \\
\text { быстрота изменения } \\
\text { скорости потока }\end{array}$ & $\begin{array}{l}\text { Ускорение струи - } \\
\text { быстрота изменения } \\
\text { скорости струи }\end{array}$ & $\begin{array}{l}\text { Ускорение элемента } \\
\text { - отношение } \\
\text { изменения скорости } \\
\text { элемента к проме- } \\
\text { жутку времени, в } \\
\text { течение которого это } \\
\text { изменение произошло }\end{array}$ \\
\hline Импульс & ТКм/ч & $\begin{array}{l}\text { Импульс потока - } \\
\text { произведение массы } \\
\text { потока на его скорость }\end{array}$ & $\begin{array}{l}\text { Импульс струи - } \\
\text { произведение массы } \\
\text { струи на её скорость }\end{array}$ & $\begin{array}{l}\text { Импульс элемента - } \\
\text { произведение массы } \\
\text { элемента потока на } \\
\text { его скорость }\end{array}$ \\
\hline Темп & $\begin{array}{l}\text { ч/км, } \\
\text { сут/км }\end{array}$ & $\begin{array}{l}\text { Teмn потока - } \\
\text { среднее время } \\
\text { прохождения потоком } \\
\text { единицы длины } \\
\text { маршрута }\end{array}$ & $\begin{array}{l}\text { Teмn cmpyu-среднее } \\
\text { время прохождения } \\
\text { струёй единицы длины } \\
\text { маршрута }\end{array}$ & $\begin{array}{l}\text { Teмn элемента - } \\
\text { среднее время } \\
\text { прохождения } \\
\text { элементом единицы } \\
\text { длины маршрута }\end{array}$ \\
\hline Интервал & $\begin{array}{l}\text { ч, } \\
\text { сут. }\end{array}$ & - & $\begin{array}{l}\text { Интервал времени } \\
\text { между элементами } \\
\text { струи - } \\
\text { время между двумя } \\
\text { следующими друг за } \\
\text { другом элементами } \\
\text { струи }\end{array}$ & $\begin{array}{l}\text { Интервал времени } \\
\text { между элементами } \\
\text { потока - } \\
\text { среднее время между } \\
\text { двумя следующими } \\
\text { друг за другом } \\
\text { элементами потока }\end{array}$ \\
\hline Работа & ткм & $\begin{array}{l}\text { Tранспортная } \\
\text { работа потока - } \\
\text { произведение массы } \\
\text { потока на длину } \\
\text { маршрута }\end{array}$ & $\begin{array}{l}\text { Tранспортная работа } \\
\text { струи - произведение } \\
\text { массы струи на длину } \\
\text { маршрута }\end{array}$ & $\begin{array}{l}\text { Tранспортная } \\
\text { работа элемента - } \\
\text { произведение массы } \\
\text { элемента на длину } \\
\text { маршрута }\end{array}$ \\
\hline
\end{tabular}

\section{2. Группа экономических показателей}

Прибыль руб. Прибыль- разница между суммарным доходом и операционными расходами

Операци- руб. Операционные расходы-сумма всех видов расходов, связанных с онные расходы
Oперационные расходы - сумма всех
превращением инвестиций в прибыль
Расчётная формула

$V=\frac{\sum V_{j} \cdot m_{j, i}}{\sum m_{j, i}} ; v_{j, i}=\frac{L}{T_{j}}=V_{j}$,

где $V, V_{j}, v_{j i}-$ скорость потока, струи и

элемента потока соответственно; $T_{j}$ - время движения элементов $j$-й струи по маршруту.

$T=\frac{L}{V} ; T_{j}=\frac{L}{V_{j}} ; t_{j, i}=\frac{L}{v_{j, i}}$,

где $T$ - время движения потока; $T_{j}$ - время движения элементов $j$-й струи по маршруту; $t_{j i}$ - время движения $i$-ого элемента $j$-ой струи по маршруту.

$\rho=\frac{M}{p_{\lambda_{z} z}}, \rho_{j}=\frac{M_{j}^{s t r}}{p_{\lambda_{z} z}}$,

где $\rho$ - плотность потока; $\rho_{j}-$ плотность $j$-й струи.

$I=\frac{M}{T} ; I_{j}=\frac{M_{j}^{s t r}}{T_{j}}$,

где $I$ - интенсивность потока; $I_{j}-$ интенсивность $j$-й струи.

$N=\rho V ; N_{j}=\rho_{j} V_{j}$,

где $N$ - мощность потока; $N_{j}$ - мощность $j$-й струи.

$a=\frac{V_{z-1}-V_{z}}{T} ; a_{j}=\frac{V_{j, z-1}-V_{j, z}}{T_{j}}$,

где $a$ - ускорение потока; $a_{j}-$ ускорение $j$-й струи.

$P=M V ; p_{j}=M_{j}^{s t r} V_{j} ; p_{j, i}=m_{j, i} v_{j, i}$,

где $P$ - импульс потока; $p_{j}-$ импульс $j$-й струи; $p_{j i}-$ импульс $i$-ого элемента $j$-ой струи.

$T_{\text {temp }}=\frac{1}{V} ; T_{\text {tempj }}=\frac{1}{V_{j}}$,

где $T_{\text {temp }}-$ транспортная работа потока; $T_{\text {tempJ }}-$ транспортная работа $j$-й струи.

$\Delta t_{j}=\frac{T_{j}}{M_{j}^{s t r}} ; \Delta t=\frac{T}{M}$,

где $\Delta t_{j}-$ интервал времени между элементами $j$-й струи; $\Delta t-$ интервал времени между элементами потока.

$A=M L ; A_{j}=M_{j}^{\text {str } L} ; A_{j, i}=m_{j, i} L$,

где $A$ - транспортная работа потока; $A_{j}-$ транспортная работа $j$-й струи; $A_{j i}-$ транспортная работа $i$-ого элемента $j$-ой струи.

$\Pi=Д-O$,

где $\Pi$ - прибыль; Д - доход; $O$ - операционные расходы.

$O=\sum_{i}^{N} o_{i}$

где $o_{i}-$ виды операционных расходов; $N-$ количество всех видов расходов логистической системы в рассматриваемом периоде. 


\begin{tabular}{|c|c|c|c|c|}
\hline \multirow{2}{*}{$\begin{array}{c}\text { Основные } \\
\text { параметры }\end{array}$} & \multirow{2}{*}{$\begin{array}{l}\text { Ед. } \\
\text { изм. }\end{array}$} & \multicolumn{3}{|c|}{ Характеристика структуры потока } \\
\hline & & Поток & Струя потока & Элемент потока \\
\hline \multirow[t]{2}{*}{$\begin{array}{l}\text { Инвестиции в } \\
\text { основной капитал }\end{array}$} & \multirow[t]{2}{*}{ руб. } & \multicolumn{3}{|c|}{$\begin{array}{l}\text { Инвестиции в основной капитал-величина денежных средств, } \\
\text { расходуемых на формирование основных средств }\end{array}$} \\
\hline & & \multicolumn{3}{|c|}{ 3. Группа энерго-экологических показателей } \\
\hline Энергоёмкость & Дж & $\begin{array}{l}\text { Энергоёмкость } \\
\text { потока - количество } \\
\text { энергии, затраченной } \\
\text { на продвижение } \\
\text { потока по маршруту }\end{array}$ & $\begin{array}{l}\text { Энергоёмкость струи } \\
\text { - количество энергии, } \\
\text { затраченной на } \\
\text { продвижение струи по } \\
\text { маршруту }\end{array}$ & $\begin{array}{l}\text { Энергоёмкость } \\
\text { элемента - } \\
\text { количество } \\
\text { энергии, затрачен- } \\
\text { ной на продвиже- } \\
\text { ние элемента по } \\
\text { маршруту }\end{array}$ \\
\hline $\begin{array}{l}\text { Тепловая } \\
\text { мощность }\end{array}$ & кBT & $\begin{array}{l}\text { Tепловая моцность } \\
\text { потока - количество } \\
\text { теплоты, выделяемое } \\
\text { потоком в единицу } \\
\text { времени }\end{array}$ & $\begin{array}{l}\text { Tепловая моцность } \\
\text { струи - количество } \\
\text { теплоты, выделяемое } \\
\text { струёй в единицу } \\
\text { времени }\end{array}$ & $\begin{array}{l}\text { Тепловая мощ- } \\
\text { ность элемента - } \\
\text { количество } \\
\text { теплоты, выделяе- } \\
\text { мое элементом в } \\
\text { единицу времени }\end{array}$ \\
\hline
\end{tabular}

Выбросы кг, Объем выбросов загрязняющих веществ - суммарный объем выбросов загрязняющих $\quad$ т $\quad$ загрязняющих веществ от всех источников, задействованных при веществ продвижении потока

Выбросы гг Объем выбросов парниковых газов - суммарный объем выбросов парниковых газов $\mathrm{CO} 2-$ парниковых газов от всех источников, задействованных при продвижеэкв. нии потока

\section{4. Группа показателей качества материальных потоков}

Сохранность перевозки Своевременность перевозки

Управляемость потока

Сохранность перевозки грузов - показатели, характеризующие перевозку без повреждений, без загрязнений, без потерь и без пропажи Своевременность перевозки грузов - показатели, характеризующие перевозку грузов к назначенному сроку, регулярность и срочность перевозки Коэффициент управляемости материального потока-отношение массы информационного потока, элементами которого являются сообщения о соблюдении показателей сохранности и своевременности перевозки, к массе управляющего информационного потока (число информационно-управляющих сообщений)

\section{5. Группа статистических показателей}

Неравномерность - $\quad$ Коэффициент неравномерности потока-отклонение значений потока

Сложность структуры потока

Дискретность потока

Дифференцируемость потока физических параметров потоков от их средних значений

Коэффициент сложности структуры потока - характеризует число струй, из которых состоит логистический поток

Коэффициент дискретности потока - характеризует число элементов, из которых состоит струя потока

Коэффициент дифференцируемости потока - характеризует изменение сложности структуры потока в процессе его движения по маршруту.
Расчётная формула

где $K$ - инвестиции в основной капитал; $K_{i}$ - количество $i$-го вида вложений на формирование основных средств.

$E=E_{\text {cmau }}+E_{\text {neped }}$

где $E_{\text {cmau }}, E_{\text {перед }}$ - соответственно количество энергии, затрачиваемой стационарными и передвижными источниками для продвижения потока на маршруте следования.

$Q=Q_{\text {cmaи }}+Q_{\text {nеред }}$

где $Q_{\text {стаи }}, Q_{\text {перед }}$ - соответственно количество тепловой энергии, выделяемой стационарными и передвижными источниками для продвижения потока на маршруте следования.

$M_{\text {Bв }}=\sum_{i}^{n} A_{i} m_{i}$

где $m_{i}$ - фактическая масса $i$-го загрязняющего выброса; $A_{i}$ - коэффициент агрессивности і-го выброса; $N$ - число видов загрязняющих выбросов.

$E m^{c}=\sum_{g} E m_{g}=\sum_{g} F u_{g} K_{g}$,

где $E m_{g}$ - объем выбросов в атмосферу парниковых газов по $g$-му типу топлива; $F u_{g}$ - количество сожжённого g-го типа топлива; $K_{g}-$ коэффициент выбросов парниковых газов по $g$-му типу топлива.

В соответствии с ГОСТ 51005-96

В соответствии с ГОСТ 51005-96

$k_{\text {упр. }}=m_{\kappa} / m_{\text {оби }}$,

где $m_{н}$ - количество сообщений о качественно выполненных управленческих решениях; $m_{\text {общ }}$ - общее количество сообщений.

$k_{\text {нер. }}=1+k_{\text {вар }} / P_{(x)}$,

где $k_{\text {вар }}$ - коэффициент вариации соответствующего параметра логистического потока; $P_{(x)}-$ среднее значение параметров. $k_{\text {слож }}=r^{20 \%} /\left(R-r^{20 \%}\right)$, где $r^{20 \%}$ - число струй, суммарная масса которых не превышает $20 \%$ от массы потока; $R$ - общее число струй в потоке.

$k_{\text {дискр. }}=\Delta t / \Delta t_{\min }, \Delta t_{\min }>0$,

где $\Delta t$ - интервал времени между элементами потока; $\Delta t_{\min }$ - минимальное, отличное от нуля значение интервала, при котором поток считается непрерывным. $k_{\text {диф }}=r_{n} / r_{1}$

где $r_{n}$ - число струй потока в конечном пункте маршрута продвижения потока; $r_{n}-$ число струй в начальном пункте. 


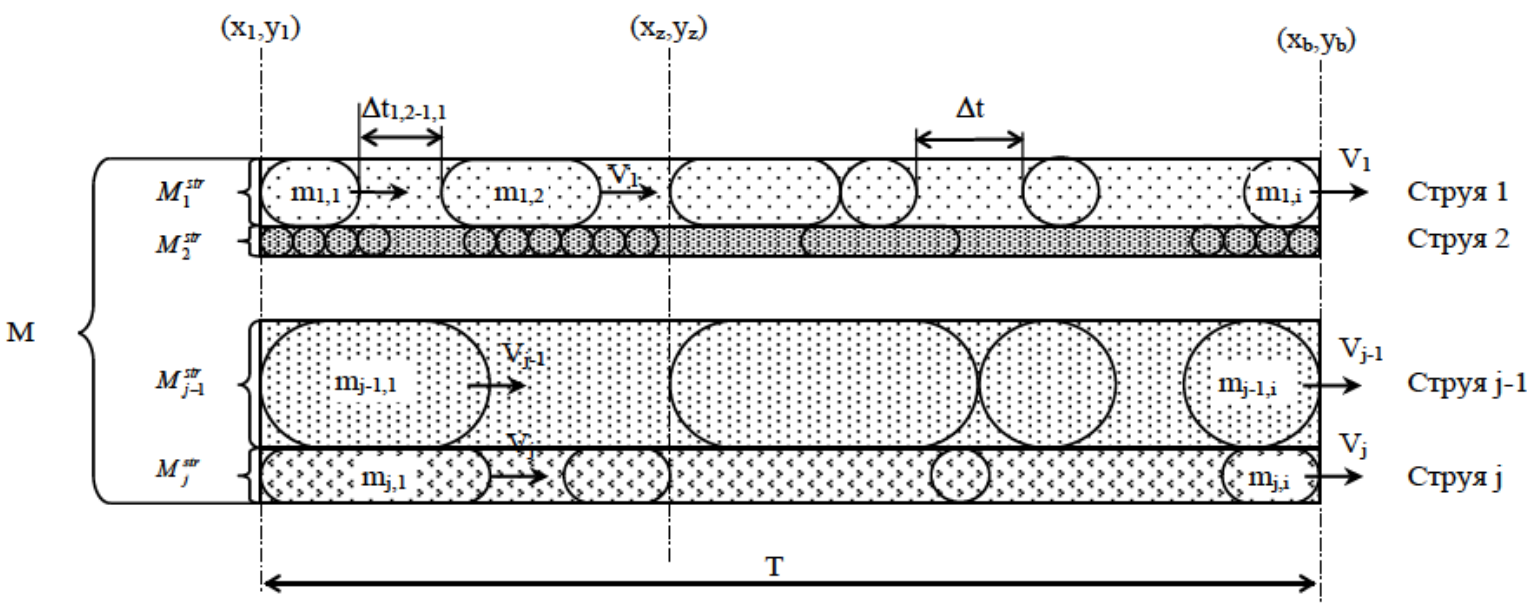

Рнс. 4. Схема структуры потока

Рассмотрнм использованне системы параметров н показателей на прнмере матернального потока логнстнческой снстемы.

Пусть нмеется матернальный поток массой $M$, рассматрнваемый в течение пернода временн $T$ как совокупность $j$-го чнсла струй массой $M_{j}^{s t r}$. Каждая струя потока состонт из $i$-го колнчества элементов, массой $m_{j, i}$. Двнженне струй (элементов) потока осушествляется по маршруту длнной $L$ со скоростью $V_{j}$ (рис. 4).

Прн движенни потока логнстнческая система взанмодействует с окружающей средой путём обмена энергней $E$ в форме теплоты $Q$ н работы $A$ - то есть к потоку подводнтся энергня (теплота) и поток совершает транспортную работу. Необходнмо поннмать, что работа выполняется всемн объектамн потока (струямн $A_{j}$ и элементамн $A_{j, i}$ ) н может рассматриваться, с одной стороны, как результат действня снлы на объект потока (элемент нлн струю). В этом случае работа равна пронзведенню модуля силы на модуль перемешення $L$, которое совершает объект под действнем снлы. С другой стороны, работу можно рассматрнвать как транспортную работу над объектамн потока, чнсленно равную пронзведенню массы объекта потока на длину маршрута движення потока.

Другнмн словамн, для оценки энергозатрат процесса продвнження потока необходнмо знать значенне снл сопротнвлення двнженню объектов потока со стороны внешней среды. Энергозатраты в этом случае зависят от велнчнн мощностн н энергни, затраченных на продвнженне потока. С точкн зрения логистнкн важным является результат выполнення транспортной услугн, выраженный в объёме перевозок или грузообороте. Прн учёте экологнческого аспекта важность прнобретают показатели выброса теплоты н загрязняющнх веществ, задействованных прн продвнженнн потока. Прн управленни «зелёнымн» цепямн поставок необходнмо формнрованне баланса между энергетнческнмн, логистическимн и экологнческнми параметрамн н показателямн процесса продвнження потоков, то есть баланса ресурсов, задействованных в этом процессе.

\section{4. Формирование ресурсного баланса в зелёных цепях поставок}

Формнрованне ресурсного баланса в зелёных цепях поставок предлагается осушествлять на основе оценкн показателей и параметров логнстнческнх потоков. Полученная оценка нспользуется для выбора и реализацни методов и ннструментов зелёной логнстнкн, представленных в [7,31,32]. Предполагается, что результатом реалнзацин каждого ннструмента является изменение определённого сочетання фнзнческнх (управляемых) параметров логнстнческнх потоков.

Предлагаемая методнка управления параметрамн потоков в зелёных цепях поставок включает следующне этапы:

1. Выполняется построенне нечёткой моделн логистнческих потоков в зелёных цепях поставок в среде fuzzyTECH [33]. Предлагаемая модель содержнт трн входных нечётких переменных, соответствующих фнзнческим параметрам потока - масса, скорость потока н длнна маршрута его двнження. Значения этнх переменных в моделн формнруются по результатам статнстнческого аналнза работы цепн поставок. В качестве промежуточных нечёткнх лннгвнстическнх переменных нспользуются трн группы показателей - экономнческне «(Economic)», энерго-экологнческне («Environment»), показатели качества («Quality»). Выходной переменной является ннтегральный показатель «устойчнвость логнстнческого потока». Схема нечёткой моделн оценкн параметров логнстнческих потоков в программе fuzzyTECH представлена на рис. 5 .

2. На основе мониторннга логнстнческих потоков цепи поставок определяются фактнческие значення нх показателей $I_{k}$, где $k=1,2, \ldots, K$ - чнсло аналнзнруемых показателей логнстическнх потоков.

3. Чнсленные значення фактнческнх показателей потоков $I_{k}$ нспользуются в качестве нсходных данных в нечёткой модели логистическнх потоков для оценки фактнческнх значеннй управляемых параметров логнстнческнх потоков $P_{i}$, где $i=1,2, \ldots, m, m=3$ чнсло управляемых параметров. 


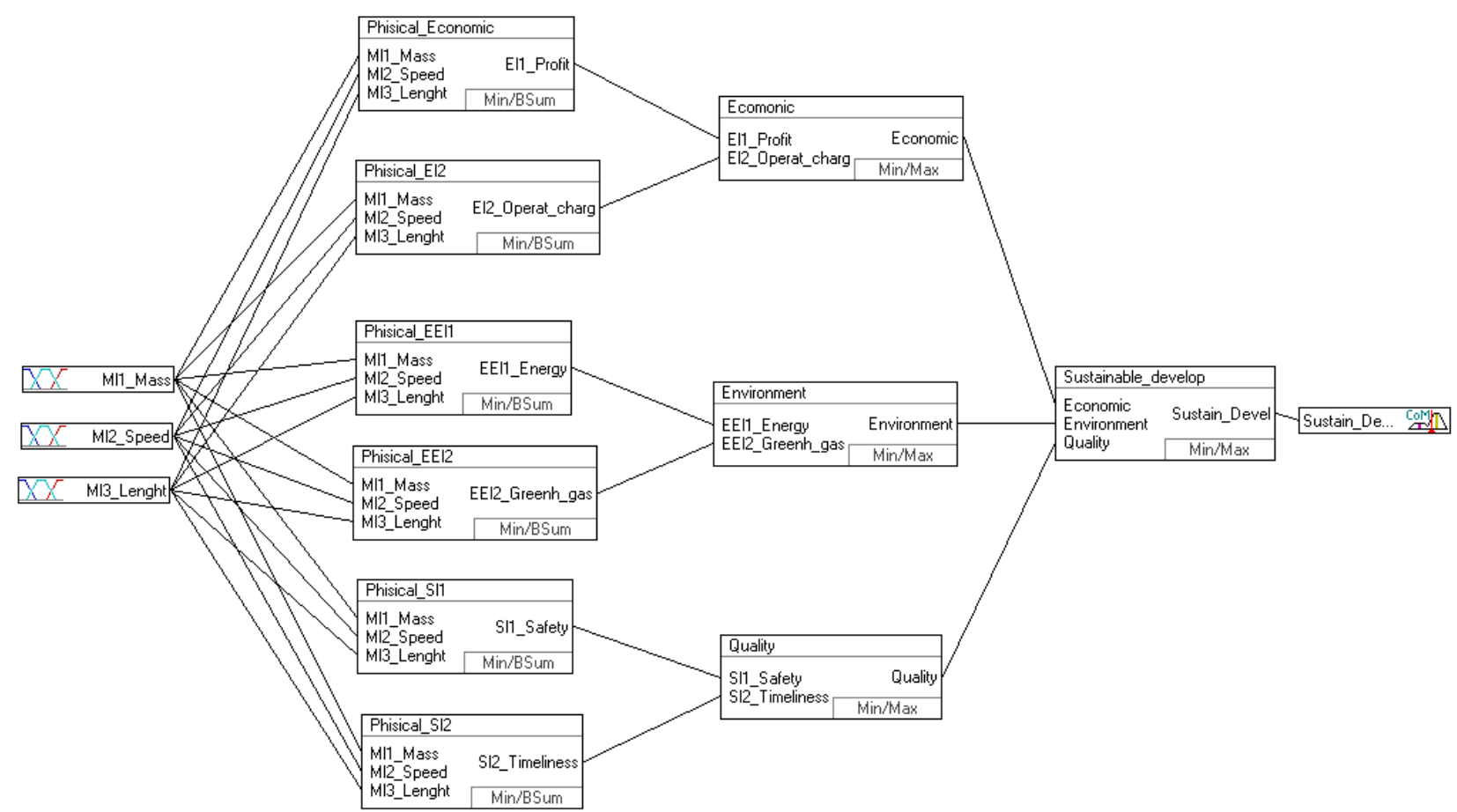

Рис. 5. Представление нечёткой модели оценки параметров логистических потоков в программе fuzzyTECH

Результатами моделирования взаимосвязи параметров и показателей потоков в нечёткой модели логистических потоков в зелёных цепях поставок в fuzzyTЕСН являются:

- $\quad$ значение интегрального показателя устойчивости цепи поставок;

- $\quad$ поверхность, описывающая зависимость интегрального показателя устойчивости цепи поставок от изменения значений физических (управляемых) параметров материальных потоков - масса, скорость и длина маршрута.

4. Определяются потребные значения показателей потоков $I^{*}{ }_{k}$. Дальнейшие действия методики направлены на расчёт значений физических (управляемых) параметров $P^{*}{ }_{i}$, которые обеспечивают достижение потребных показателей потоков $I^{*}{ }^{*}$.

5. Рассчитывается разница между требуемыми и фактическими значениями управляемых параметров $\Delta P_{i}=P_{i}^{*}-P_{i}, \forall i$.

6. Формируется матрица вариантов изменения параметров логистических потоков

$$
\left\|t_{i j}\right\|\left(i=1,2, \ldots, m ; j=1,2, \ldots, A_{m}^{\prime n}\right),
$$

где $j$ - порядковый номер комбинации параметров, $A_{m}^{\prime n}$ - количество возможных комбинаций, определяемое как число размещений с повторениями $m=3$ элементов матрицы (параметров потоков) по $n$ позициям (вариантам изменения значения каждого параметра); $n=3$ - число вариантов изменения значений параметров потоков: «уменьшение», «увеличение» и «без изменений», $A_{3}^{\prime 3}=27$. Для рассматриваемого примера матрица $\left\|t_{i j}\right\|$ запишется следующим образом

$$
\left\|t_{i j}\right\|=\left(\begin{array}{rrr}
1 & 1 & 1 \\
1 & 1 & -1 \\
1 & -1 & 1 \\
1 & -1 & -1 \\
-1 & 1 & 1 \\
-1 & 1 & -1 \\
-1 & -1 & 1 \\
-1 & -1 & -1 \\
1 & 0 & 0 \\
-1 & 0 & 0 \\
0 & 1 & 0 \\
0 & -1 & 0 \\
0 & 0 & 1 \\
0 & 0 & -1 \\
1 & 1 & 0 \\
1 & -1 & 0 \\
-1 & 1 & 0 \\
-1 & -1 & 0 \\
1 & 0 & 1 \\
1 & 0 & -1 \\
-1 & 0 & -1 \\
0 & 1 & 1 \\
0 & 1 & -1 \\
0 & -1 & 1 \\
0 & -1 & 1 \\
0 & -1 & -1 \\
0 & 0 & 0
\end{array}\right)
$$


7. В матрице $\left\|t_{i j}\right\|$ выбирается вариант изменения параметров логистических потоков $V$. Номер варианта соответствует номеру строки матрицы $\left\|t_{i j}\right\|$, если выполняется условие

$\left(\operatorname{sgn}\left\|t_{1 j}\right\|=\operatorname{sgn} \Delta P_{1}\right)^{\wedge}\left(\operatorname{sgn}\left\|t_{2 j}\right\|=\operatorname{sgn} \Delta P_{2}\right)^{\wedge}\left(\operatorname{sgn}\left\|t_{3 j}\right\|=\right.$ $\left.=\operatorname{sgn} \Delta P_{3}\right) \rightarrow V=j, j=1,2, \ldots, A_{m}^{\prime n}$.

Взаимосвязь основных параметров логистических потоков и инструментов зелёной логистики (на примере транспортного элемента)

\begin{tabular}{|c|c|c|c|c|}
\hline \multirow{2}{*}{$\begin{array}{l}\text { № } \\
\text { вари- } \\
\text { анта } V \\
\end{array}$} & \multirow[t]{2}{*}{ Наименование инструмента зелёной логистики } & \multicolumn{3}{|c|}{$\begin{array}{c}\text { Знак изменения } \\
\text { параметра потока }\end{array}$} \\
\hline & & $\Delta M$ & $\Delta S$ & $\Delta L$ \\
\hline 1 & Использование интермодальных технологий и смешанных перевозок & + & + & + \\
\hline 2 & Выбор рациональных базисных условий поставки & + & + & - \\
\hline 3 & Выбор экологичных видов транспорта & + & - & + \\
\hline 4 & $\begin{array}{l}\text { Выбор транспортных средства с большей грузоподъёмностью (грузо- } \\
\text { вместимостью) }\end{array}$ & + & - & - \\
\hline 5 & $\begin{array}{l}\text { Изменение качественных показателей потоков или потребностей в } \\
\text { потоках }\end{array}$ & - & + & + \\
\hline 6 & Минимизация объёмов закупок & - & + & - \\
\hline 7 & $\begin{array}{l}\text { Использование транспортных средств с наименьшим воздействием на } \\
\text { окружающую среду }\end{array}$ & - & - & + \\
\hline 8 & $\begin{array}{l}\text { Выбор транспортных средств, соответствующих установленным } \\
\text { экологическим требованиям }\end{array}$ & - & - & - \\
\hline 9 & Повышение уровня загрузки транспортных средств & + & const & const \\
\hline 10 & $\begin{array}{l}\text { Оперативное управление параметрами материальных потоков для } \\
\text { обеспечения равномерной загрузки элементов транспортной инфра- } \\
\text { структуры, уменьшения заторов и запасов }\end{array}$ & - & const & const \\
\hline 11 & Оптимизация скорости движения транспортных средств & const & + & const \\
\hline 12 & Эко-вождение & const & - & const \\
\hline 13 & $\begin{array}{l}\text { Выбор способов поставки с учётом минимального воздействия на } \\
\text { окружающую среду }\end{array}$ & const & const & + \\
\hline 14 & Выбор эко-дружественных поставщиков & const & const & - \\
\hline 15 & Консолидация грузопотоков по направлениям & + & + & const \\
\hline 16 & Сокращение частоты поставок & + & - & const \\
\hline 17 & Оперативный контроль параметров системы управления запасами & - & + & const \\
\hline 18 & $\begin{array}{l}\text { Использование экологичных горюче-смазочных материалов (видов } \\
\text { топлива) }\end{array}$ & - & - & const \\
\hline 19 & $\begin{array}{l}\text { Сокращение итераций и звеньев в цепи поставок (сокращение пунктов } \\
\text { перевалки и хранения грузов) }\end{array}$ & + & const & + \\
\hline 20 & Уменьшение обратного порожнего пробега & + & const & - \\
\hline 21 & Использование многооборотной тары и упаковки & - & const & + \\
\hline 22 & $\begin{array}{l}\text { Обеспечение технологического единства транспортно-складского } \\
\text { процесса }\end{array}$ & - & const & - \\
\hline 23 & Использование технологии радиочастотной идентификации & const & + & + \\
\hline 24 & Оптимизация маршрутов движения транспортных средств & const & + & - \\
\hline 25 & Оптимизация структуры грузопотоков & const & - & + \\
\hline 26 & Выбор близкорасположенных поставщиков & const & - & - \\
\hline 27 & Внесение экологических аспектов в стратегию организации & const & const & const \\
\hline
\end{tabular}

Рассмотрим в качестве примера реализацию предлагаемой в работе методики управления параметрами логистических потоков в зелёных цепях поставок. Перевозка грузов в цепи поставок между двумя городами с использованием автомобильного транспорта. Фактические значения параметров и показателей исследуемой цепи поставок представлены в табл. 4.
8. Осуществляется реализация выбранного инструмента зелёной логистики [7] (табл. 3) для приведения показателей логистических потоков в соответствие с потребными значениями.

Таблица 3

На основании анализа данных о функционировании цепи поставок выбраны показатели, не удовлетворяющие требованиям экологичности: повышенная энергоёмкость; большой объем выбросов парниковых газов. Для приведения показателей логистических потоков в соответствие с требуемыми значениями выбирается инструмент зелёной логистики.

Анализ возможностей реализации инструментов

\section{6 https://transcience.ru —— Современные проблемы транспортного комплекса России. 2019. T.9. №1}


зелёной логистики, применительно к рассматриваемой цепи поставок, позволил выделить 3 инструмента: оптимизация скорости движения (V11); оптимизация маршрутов (V24); использование экологичных видов транспорта (V3). Реализация остальных инструментов зелёной логистики для анализируемых условий не является целесообразной.

Исходные данные и результаты моделирования потоков зелёной цепи поставок

Таблица 4

\begin{tabular}{|c|c|c|c|c|}
\hline \multirow{3}{*}{ Наименование показателей и параметров логистических потоков } & \multicolumn{4}{|c|}{ Значение параметров (показателей) / Вариант } \\
\hline & \multirow{2}{*}{$\begin{array}{c}\text { Фактическое } I_{k} \\
-\end{array}$} & \multicolumn{3}{|c|}{ Требуемое $I_{k}^{*}$} \\
\hline & & V11 & V24 & V3 \\
\hline Масса потока, т & 200 & 200 & 200 & 200 \\
\hline Скорость потока, км/сут. & 400 & 550 & 450 & 270 \\
\hline Длина маршрута потока, км & 1850 & 1850 & 1793 & 1764 \\
\hline Энергоёмкость потока, литр / 100 ткм & 6 & 6 & 6 & 0.6 \\
\hline Объем выбросов парниковых газов, г/ткм & 104 & 104 & 104 & 31 \\
\hline Коэффициент неравномерности потока & 1.1 & 1.1 & 1.1 & 1.0 \\
\hline Коэффициент сложности структуры потока & 0.9 & 0.9 & 0.9 & 0.9 \\
\hline Коэффициент дискретности потока & 0.25 & 0.25 & 0.1 & 0.9 \\
\hline Коэффициент дифференцируемости потока & 1.0 & 1.0 & 1.0 & 1.0 \\
\hline Интегральный показатель устойчивости цепи поставок & 0.125 & 0.307 & 0.1357 & 0.4027 \\
\hline
\end{tabular}

Параметры логистических потоков

Macca -

Длина

маршрута -

Устойчивость

Скорость -

Длина

маршрута -

Устойчивость

Macca -

Скорость -

Устойчивость
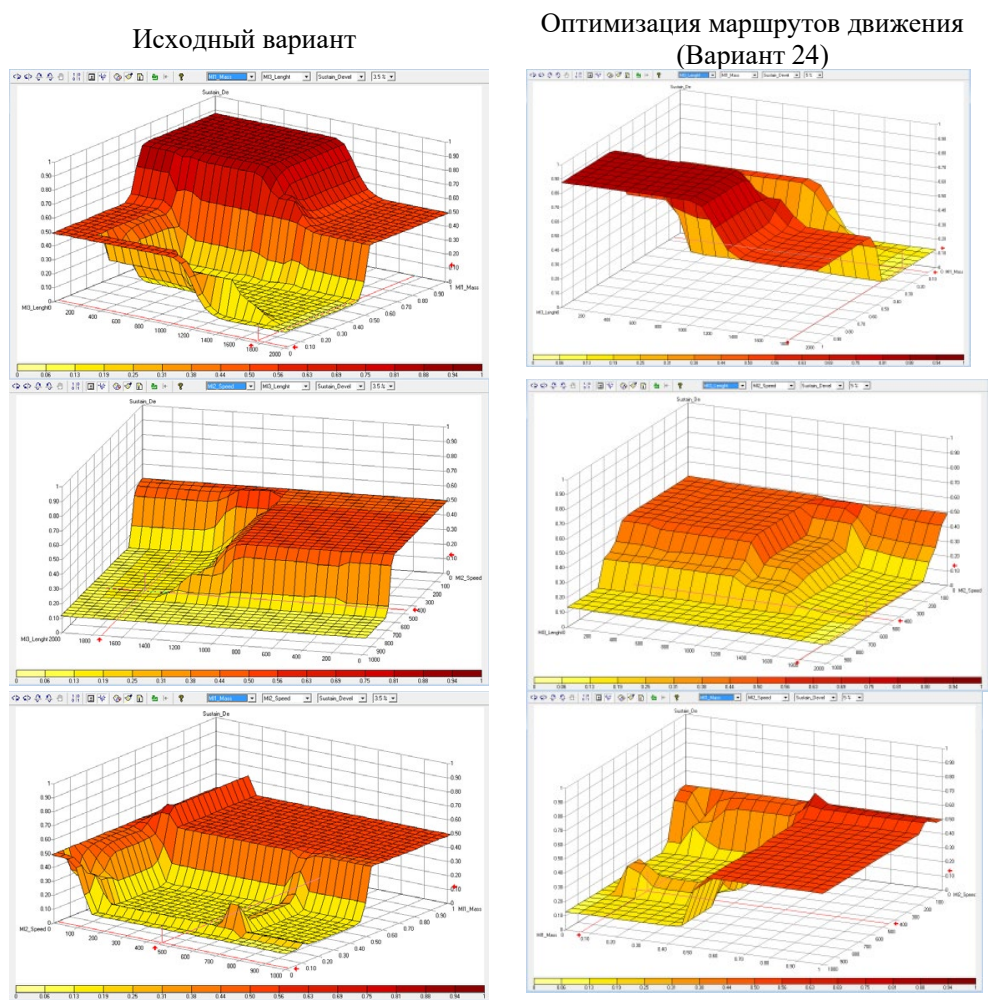

Использование экологичных видов транспорта (Вариант 3)

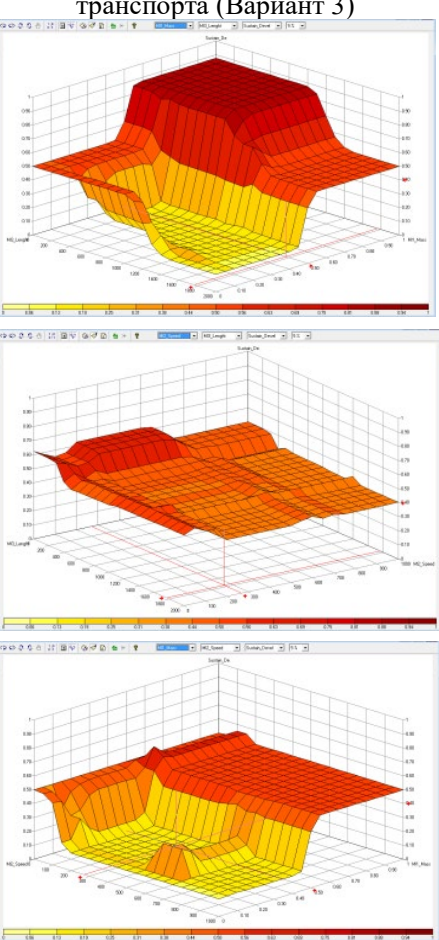

Рис. 6. Результаты оценки устойчивости цепи поставок

В качестве примера на рис. 6 представлены поверхности, описывающие влияние нечётких значений управляемых параметров логистических потоков на величину устойчивости цепи поставок для трёх вариантов: исходного (наименьшая устойчивость $0.125)$; при реализации инструментов «Оптимизация маршрута движения» (устойчивость - 0.1357) и «Использование экологичных видов транспорта» (наибольшая устойчивость - 0.4027).

Таким образом, для приведения показателей логистических потоков в соответствие с требуемыми значениями наиболее эффективным в рассматриваемом примере является инструмент «Использование экологичных видов транспорта» (переход от автомобильных к железнодорожным перевозкам). Наименее эффективным - инструмент «Оптимизация маршрутов движения транспортных средств».

\section{5. Заключение}

Для эффективной реализации концепции устойчивого развития в логистической деятельности и управлении цепями поставок необходимо применять методы выработки управленческих решений по изменению параметров логистических потоков на основе измерения и оценки их показателей. Сложность управления зелёными цепями поставок заклю- 
чается в недостаточной исследованности закономерностей, описывающих взаимосвязи параметров и показателей логистических потоков, в отсутствии комплексного подхода к оценке данных параметров. Кроме того, имеет место бессистемное применение на практике разнообразных методов и инструментов управления потоками в цепях поставок.

В настоящей работе предложена оригинальная система индикаторов (показателей и параметров) логистических потоков, включающая в себя четыре группы показателей: энерго-экологические показатели; экономические показатели; показатели качества; статистические показатели. К основным физическим (управляемым) параметрам потоков отнесены: масса потока; скорость движения потока; длина маршрута движения потока.

Идея формирования ресурсного баланса в цепи поставок построена на оценке показателей логистических потоков и формирования такого сочетания физических (управляемых) параметров логистических потоков, которое обеспечивает функционирование логистической системы в соответствии с принципами концепции устойчивого развития. Для оценки показателей логистических потоков разработана нечёткая модель. Предложен способ корректировки параметров потоков с целью приведения фактических значений показателей этих потоков к требуемым. Формирование ресурсного баланса предлагается достигать на основе использования системы инструментов зелёной логистики, позволяющей корректировать параметры потоков.

Использование предлагаемой в работе методики позволит: повысить качество оценки состояния потоков в цепях поставок по критерию соответствия целям концепции устойчивого развития; повысить эффективность реализации решений по управлению потоками в цепях поставок на основе использования системы методов и инструментов «зелёной» логистики.

\section{Список литературы}

1. The Sustainable Development [Электронный pecypc]. URL https://sustainabledevelopment.un.org/ (дата обращения: 06.02.2018).

2. Sustainable development of transport systems for cargo flows on the EastWest direction / Rakhmangulov A., Sładkowski A., Osintsev N., Kopylova O., Dyorina N. Sustainable Development of Transport Systems for Cargo Flows on the East-West Direction: 2018. vol. 156. pp. 3-69. doi: 10.1007/978-3-319-78295-9_1.

3. Осинцев Н.А., Рахмангулов А.Н., Сладковский А.В., Багинова В.В. Систематизация принципов «зелёной» логистики (Часть 1. Анализ существующих принципов логистики и устойчивого развития) // Бюллетень транспортной информации. 2019. 1(283). С. 10-16.

4. Осинцев Н.А., Рахмангулов А.Н., Сладковский А.В., Багинова В.В. Систематизация принципов «зелёной» логистики (Часть 2. Синтез принципов логистики и устойчивого развития) // Бюллетень транспортной инсоормации. 2019. Т. 2(284). С. 7-16.

5. Rakhmangulov A., Sladkowski A., Osintsev N., Muravev D. Green Logistics: Element of the Sustainable Development Concept. Part $1 / 1$ Naše more. 2017. T. 64. № 3. C. 120-126. doi: 10.17818/NM/2017/3.7.

6. Показатели энергоэффективности: основы формирования политики
OECD/IEA, International Energy Agency. Paris, 2014. 178 c.

7. Rakhmangulov A., Sladkowski A., Osintsev N., Muravev D. Green Logistics: A System of Methods and Instruments - Part 2 // Naše more. 2018. T. 65. № 1. C. 49-55. doi: 10.17818/NM/2018/1.7.

8. Ивуть Р.Б., Нарушевич С.А. Логистика. Минск: БНТУ, 2004. 328 с

9. Корнилов С.Н., Рахмангулов А.Н., Шаульский Б.Ф. Основы логистики: Учеб. пособие. Москва: ФГБОУ "Учебно-методический центр по образованию на железнодорожном транспорте", 2016. 302 c.

10. Миротин Л.Б., Сергеев В.И. Основы логистики: Учеб. пособие. М.: ИНФРА-М, 1999. $200 \mathrm{C}$.

11. Поттгофф Г. Учение о транспортных потоках: Пер. с нем. М.: Транспорт, 1975. 344 c.

12. Дрю Д. Теория транспортных потоков и управление ими. М. Транспорт, 1972. 424 C.

13. Миротин Л.Б., Гудков В.А., Зырянов В.В. Управление грузовыми потоками в транспортно-логистических системах. М.: Горячая линияТелеком, 2010.704 с

14. Иносэ Х., Хамада Т. Управление дорожным движением. М.: Транспорт, 1983. $248 \mathrm{c}$

15. Григорьев М.Н., Уваров С.А. Логистика.: Базовый курс: учебник для бакалавров. М.: Издательство Юрайт, 2012. 818 с.

16. Галяутдинов P.Р. Механизмы взаимодействия потоков и запасов на предприятии с точки зрения логистики // Вестник ЮУрГУ. Серия «Экономика и менеджмент». 2016. Т. 10. № 1. С. 157-163.

17. Osintsev N., Rakhmangulov A., Sladkowski A., Jian G. J. The system of resource balance indicators in green supply chains. // Transport Problems - 2019 Proceeding XI International Scientific Conference, 26-28 june 2019, Katowice: Selesian University of Technology. pp. 472-479.

18. Семенов В.В. Смена парадигмы в теории транспортных потоков. Преприн № 46. М.: ИПМ им. М.В. Келдыша, 2006. 32 с.

19. Швецов В.И. Математическое моделирование транспортных потоков // Автоматика и телемеханика. 2003. № 11. С. 3-46.

20. Введение в математическое моделирование транспортных потоков: учеб. пособие / Под ред. А.В. Гасникова. М.: МФТИ, 2010. 360 с.

21. Минаков В.Ф. Производственная функция в логистических потоках // Международный научно-исследовательский журнал. 2014. 11-3(30). C. $55-58$.

22. Семенов В.В. Математическое моделирование динамики транспортных потоков мегаполиса. Препринт №34, 2004. 38 c.

23. Неруш Ю.М. Логистика. М.: ТК Велби, Изд-во Проспект, 2006. 520 с.

24. Вол М., Мартин Б. Анализ транспортных систем.: пер. с англ. М.: Транспорт, $1981.516 \mathrm{c}$.

25. Тяпухин А.П. Логистика. 2-е изд. М.: Юрайт, 2013. 568 с.

26. Тяпухин А.П. Кодировка и графическая интерпретация параметров погистических потоков // Вопросы современной экономики. 2013. № 4. $131-144$.

27. Козлов П.А. Поток и бункер-канал в транспортной системе // Мир транспорта. 2014. Т. 12. 2(51). С. 30-37.

28. Филонов Н.Г. Анализ структуры совокупных издержек при формировании потока инноваций в логистических (экономических) системах // Вестник Томского государственного педагогического университета. 2012. 12(127). C. 133-140.

29. Филонов Н.Г., Коваленко Л.В., Дащинская С.К. Анализ потоков в логистических системах // Вестник Томского государственного университета. 2007. 300-2. С. 77-79.

30. Минаков В.Ф., Минакова Т.Е. Метрика потока в информационной логистике // Международный научно-исследовательский журнал. 2014. 4-1 (23). C. 63-64.

31. Осинцев Н.А., Рахмангулов А.Н. Система методов и инструментов зелёной логистики в цепях поставок / Транспорт и логистика: инновационное развитие в условиях глобализации технологических и экономических связей. Ростов-на-Дону: Рост. гос. ун-т. путей сообщения. 2018. C. $274-278$

32. Rakhmangulov A., Sladkowski A., Osintsev N., Muravev D. An approach to achieving the sustainable development goals based on the system of green logistics methods and instruments // Transport Problems - 2017 Proceeding IX International Scientific Conference, 28-30 june 2017, Katowice: Selesian University of Technology, pp. 541-556.

33. FuzzyTECH [Электронный ресурc]. URL: https://fuzzytech.com/ (дата обращения: 06.02.2018)

Материал поступил в редакцию 28.05.2019

Осинцев Н.А. Параметры и показатели потоков в зелёных цепях поставок // Современные проблемы транспортного комплекса России. 2019. Т.9. №1. С. 27-40 


\title{
FLOW INDICATORS IN GREEN SUPPLY CHAINS
}

\author{
Nikita Osintsev ${ }^{1}$ \\ ${ }^{1}$ Nosov Magnitogorsk State Technical University, Magnitogorsk, Russia
}

\section{Abstract}

The complexity of managing green supply chains is associated with insufficient knowledge of the system of logistic flow indicators and parameters, as well as with the absence of methods for their comprehensive assessment of compliance with the principles of the sustainable development concept. The results of the analysis logistic flow indicators are presented in the paper. It has been determined that the generally accepted logistic management criteria do not consider environmental and social aspects, which reduces the effective-ness of managing logistic flows in accordance with the requirements of the sustainable development concept. In the present work an original system of indicators of logistic flows in green supply chains is proposed. Manageable parameters of logistic flows are identified. Their modification ensures the implementation of principles of the sustainable development concept. A fuzzy model for managing the parameters of logistics flows has been developed. The formation of resource balance in the logistics system approach is proposed, ensuring the functioning of the logistics system in accordance with the principles of the sustainable development concept.

Keywords: logistics flows, green supply chain management, sustainable development, transport system, parameters, indicators, green logistics, fuzzy approach.

\section{References}

1. The Sustainable Development. Available at https://sustainabledevelopment.un.org/.

2. Sustainable development of transport systems for cargo flows on the EastWest direction / Rakhmangulov A., Stadkowski A., Osintsev N., Kopylova O., Dyorina N. Sustainable Development of Transport Systems for Cargo Flows on the East-West Direction: 2018. vol. 156. pp. 3-69. doi 10.1007/978-3-319-78295-9_1.

3. Osintsev N. A., Rakhmangulov A. N., Sladkovskii A. V., Baginova V. V. Sistematizatsiia printsipov "zelenoi» logistiki (Chast 1. Analiz sushchestvuiushchikh printsipov logistiki i ustoichivogo razvitiia) [Systematization of the green logistics' principles. Part 1 . The analysis of the existing logistics' and sustainable development principles] // Biulleten transportnoi informatsii [the Bulletin of Transport Information]. 2019 1(283), pp. 10-16. (In Russ.)

4. Osintsev N. A., Rakhmangulov A. N., Sladkovskii A. V., Baginova V. V. Sistematizatsiia printsipov «zelenoi» logistiki (Chast 2. Sintez printsipov logistiki i ustoichivogo razvitia) [Systematization of the green logistics principles. Part 2. Synthesis of the principles of logistics and sustainable development] // Biulleten transportnoi informatsii [the Bulletin of Transport Information]. 2019, 2(284), pp. 7-16.

5. Rakhmangulov A., Sladkowski A., Osintsev N., Muravev D. Green Logistics: Element of the Sustainable Development Concept. Part $1 /$ Naše more 2017 vol 64 no 3 pp. 120-126. doi: $10.17818 /$ NM/2017/3.7.

6. Pokazateli energoeffektivnosti: osnovy formirovaniia politiki [Energy efficiency indicators: policy framework]. Paris: International Energy Agency. 2014. 178 p. (In Russ.).

7. Rakhmangulov A., Sladkowski A., Osintsev N., Muravev D. Green Logistics: A System of Methods and Instruments - Part 2 // Naše more. 2018 , vol. 65 , no. 1 , pp. $49-55$. doi: $10.17818 / \mathrm{NM} / 2018 / 1.7$.

8. Ivut R. B., Narushevich S. A. Logistika [Logistics]. Minsk: Belarusian National Technical University. 2004. 328 p. (In Russ.)

9. Kornilov S. N., Rakhmangulov A. N., Shaulskii B. F. Osnovy logistiki Textbook [Fundamentals of logistics: Textbook]. Moscow: FGBOU «Educational-methodical center of education on railway transport». 2016 302 p. (In Russ.)

10. Mirotin L. B., Sergeev V. I. Osnovy logistiki [Basics of logistics]. Moscow: INFRA-M. 1999. 200 p. (In Russ.)

11. Pottgoff G. Uchenie o transportnykh potokakh [Traffic flow theory] Moscow: Transport. 1975. 344 p. (In Russ.).

12. Driu $D$. Teoriia transportnykh potokov i upravlenie imi [Traffic flow theory and control]. Moscow: Transport. 1972. 424 p. (In Russ.)

13. Mirotin L. B., Gudkov V. A., Zyrianov V. V. Upravlenie gruzovymi potokami v transportno-logisticheskikh sistemakh [Cargo flow management in transport and logistics systems]. Moscow: Goryachaya liniya-Telekom. 2010.704 p. (In Russ.).

14. Inose K., Khamada T. Upravlenie dorozhnym dvizheniem [Road traffic control]. Moscow: Transport. 1983. 248 p. (In Russ.)

15. Grigorev M. N., Uvarov S. A. Logistika [Logistics]. Moscow: Izdatelstvo Urait. 2012. 818 p. (In Russ.)

16. Galyautdinov R. R. Mekhanizmy vzaimodeistviia potokov i zapasov na predpriiatii s tochki zreniia logistiki [The mechanisms of interaction of flows and stocks at enterprise from the perspective of logistics] // Bulletin of the South Ural State University. Ser. Economics and Management. 2016, vol. 10, no. 1, pp. 157-163. doi: 10.14529/em160119. (In Russ.)

17. Osintsev N., Rakhmangulov A., Sladkowski A., Jian G. J. The system of resource balance indicators in green supply chains // Transport Problems 2019 Proceeding XI International Scientific Conference, 28-30 June 2019. Katowice: Silesian University of Technology, pp. 472-479

18. Semenov V. V. Smena paradigmy $v$ teorii transportnykh potokov [Paradigm shift in the theory of transport flows]. Moscow: Keldysh Institute of Applied Mathematics. 2006. 32 p. (In Russ.)

19. Shvetsov V. I. Matematicheskoe modelirovanie transportnykh potokov [Mathematical modeling of transport flows] // Avtomatika i Telemekhanika [Automation and Remote Controll. 2003 no 11 pp. 3-46. (In Russ).

20. Vvedenie $\mathrm{v}$ matematicheskoe modelirovanie transportnykh potokov [Introduction to mathematical modelling of transport flows]. Moscow: Moscow Institute of Physics and Technology. 2010. 360 p. (In Russ.).

21. Minakov V. F. Proizvodstvennaia funktsiia v logisticheskikh potokakh [Production function in logistic streams] // Mezhdunarodnyi nauchnoissledovatelskii zhurnal [Research Journal of International Studies]. 2014, 11-3(30), pp. 55-58. (In Russ.).

22 Semenov V V Matematicheskoe modelirovanie dinamiki transportnykh potokov megapolisa. Preprint №34 [Mathematical modelling of the dynamics of metropolis transport flows]. Moscow: 2004. 38 p. (In Russ.).

23. Nerush I.M. Logistika [Logistics]. Moscow: TK Velbi, Izd-vo Prospekt. 2006.520 p. (In Russ.)

24. Vol M., Martin B. Analiz transportnykh sistem [Traffic system analysis]. Moscow: Transport. 1981. 516 p. (In Russ.)

25. Tyapukhin A. P. Logistika [Logistics]. Moscow: Urait. 2013. 568 p. (In Russ.).

26. Tyapukhin A. P. Kodirovka i graficheskaia interpretatsiia parametrov logisticheskikh potokov [Coding and graphical interpretation of logistic flow parameters] // Voprosy sovremennoi ekonomiki [lssues of the modern economy]. 2013 no. 4, 131-144 (In Russ).

27. Kozlov P. A. Potok i bunker-kanal v transportnoi sisteme [Flow and bunker-channel in the transport system] // Mir transporta [World of Transport]. 2014, vol. 12, 2(51), pp. 30-37. (In Russ.).

28. Filonov N. G. Analiz struktury sovokupnykh izderzhek pri formirovani potoka innovatsii v logisticheskikh (ekonomicheskikh) sistemakh The Analysis of structure of cumulative costs while forming the production line of innovations in logistic (economic) systems] // Vestnik Tomskogo gosudarstvennogo pedagogicheskogo universiteta [TSPU Bulletin]. 2012, 12(127), pp. 133-140. (In Russ.)

29. Filonov N. G., Kovalenko L. V., Dashchinskaia S. K. Analiz potokov 
logisticheskikh sistemakh [The analysis of the structure of continuums in logistic systems] // Vestnik Tomskogo gosudarstvennogo pedagogicheskogo universiteta [TSPU Bulletin]. 2007, 300-2, pp. 77-79. (In Russ.)

30. 30. Minakov, V.F. \& Minakova, T.E. Metrika potoka $v$ informatsionno logistike [Stream metrics in information logistics] // Mezhdunarodnyi nauchno-issledovatelskii zhurnal [Research Journal of International Studies]. 2014, 4-1 (23), pp. 63-64. (In Russ.).

31. Osintsev N.A., Rakhmangulov A.N. Sistema metodov i instrumentov zelenoi logistiki $v$ tsepiakh postavok [System of green logistics methods and instruments in supply chains] // Transport i logistika: innovatsionnoe razvitie $v$ usloviiakh globalizatsii tekhnologicheskikh i ekonomicheskikh sviazei Transport and Logistics: innovate development in the conditions of globalization of technological and economic relations]. Rostov-on-Don: Rostov State Transport University, 2018, pp. 274-278. (In Russ.).

32. Rakhmangulov A., Sladkowski A., Osintsev N., Muravev D. An approach to achieving the sustainable development goals based on the system of green logistics methods and instruments // Transport Problems - 2017 Proceeding IX International Scientific Conference, 28-30 June 2017. Katowice: Silesian University of Technology, pp. 541-556.

33. FuzzyTECH. Available at: https://fuzzytech.com/.

Osintsev N. Flow indicators in green supply chains // Modern Problems of Russian Transport Complex. 2019, vol.9, no.1, pp. 27-40 